\title{
Socioeconomic Inequality in Fruit and Vegetable Consumptions in Elderly People: A Cross Sectional Study in North West of Iran
}

\author{
Amin Mokari-Yamchi ${ }^{1}$, Saeid Sadeghian-Sharif ${ }^{1}$, Elyas Nattagh-Eshtivani ${ }^{2}$, Ammar Salehi-Sahlabadi ${ }^{3}$, Abed Ghavami ${ }^{4}$, Meisam \\ Barati $^{5}$, Mehrangiz Ebrahimi-Mameghani ${ }^{6^{*}}$ \\ 1- Department of Community Nutrition, Faculty of Nutrition Sciences and Food Technology, Shahid Behehshti University of Medical Sciences, Tehran, \\ Iran. \\ 2- Student Research Committee, Mashhad University of Medical Sciences, Mashhad, Iran. \\ 3- Department of Clinical Nutrition and Dietetics, Faculty of Nutrition Sciences and Food Technology, Shahid Beheshti University of Medical Sciences, \\ Tehran, Iran. \\ 4- Student Research Committee, Department of Clinical Nutrition, School of Nutrition and Food Science, Isfahan University of Medical Sciences, \\ Isfahan, Iran. \\ 5- Department of Cellular and Molecular Nutrition, Faculty of Nutrition and Food Technology, Shahid Beheshti University of Medical Sciences, Tehran, \\ Iran. \\ 6- Nutrition Research Center, Department of Community Nutrition, School of Nutrition, Tabriz University of Medical Sciences, Tabriz, Iran.
}

\section{A B S T R A C T}

Background and Objectives: High fruit and vegetable (FV) consumption has been shown to protect humans against chronic diseases in elderly people. As several factors can affect FV consumption, the aim of this study was to investigate associations between the socioeconomic status and FV consumption in elderly people.

Materials and Methods: This population-based cross-sectional study was carried out on 238 elderly people, aged over 65 years and living in Marand, northwest of Iran. Consumption of FV was assessed using validated 110-item food frequency questionnaire (FFQ). The participants were selected from seven health care centers.

Results: The mean age of the participants was $71.7 \pm 4.1$ years with $65.5 \%$ were males. The adequate daily consumption of FVs (totally $400 \mathrm{~g}$ or more) was reported in $58 \%$ of the participants. Old ages and low educational levels were associated to low consumption of FVs $(P<0.05)$. High incomes and marriage statuses were significantly associated to high consumption of fruits $(P<0.001)$. High consumption of vegetables was seen in people with lower economic status. The logistic regression analysis showed that the chance of FV consumption in participants who owned a house, got married or had a high income was 3.05, 2.02 and 2.39 times greater, respectively.

Conclusions: This study has demonstrated important roles of the socioeconomic factors such as household income level, gender and marital and educational statuses on consumption of FVs. Therefore, our results suggest that, the future policies and interventions to improve the consumption of FVs in elderly people should consider socioeconomic inequalities.

Keywords: Fruit, Vegetable, Elderly People, Socioeconomic, Iran

\section{Introduction}

Fruits and vegetables (FVs) are rich sources of micronutrients and considered as important components of healthy diets (1). High consumption of FVs has been shown to be protective against obesity (2) diabetes (3), hypertension (4), stroke (5), cancer (6) and osteoporosis (7). These diseases are mostly prevalent in elderly populations $(8,9)$. It was estimated in 2003 that inadequate consumption of FVs was attributed to 5.2 million deaths (1). The World Health Organization (WHO) has recommended a minimum intake of $400 \mathrm{~g}$ or five servings of FVs per day (10). Evidences suggest that consumption of 
FVs decreases with decreases in age in countries with middle to high gross domestic product (GDP) such as Iran and USA (11-13). Recently, attentions have raised toward the effects of socioeconomic and environmental factors on food choices. Studies have suggested that the low consumption of FVs is strongly associated to socioeconomic status, including male gender, old age, low education, low income and being single, widow or divorced $(4,12,14-16)$.

Iran is one of the countries with growing elderly and hence needs proper health policies (17). A population based study on 400 elderly people from 23 nursing houses in Tehran using food frequency questionnaire (FFQ) showed that consumption of FVs was lower than the recommended level $\left(400 \mathrm{~g} \mathrm{day}^{-1}\right)$ and associated to age, marital status, educational level and income level (12). In a Brazilian study on 2,066 low-income elderly people in Sao Paulo, 2009, nearly $20 \%$ of the people consumed sufficient FVs. Furthermore, consumption was positively linked to income and years of schooling (18). Previous studies have majorly carried out in metropolitans. Limited results are available for the consumption of FVs in small cities and rural regions; therefore, this study was carried out to investigate consumption of FVs and associated factors in elderly people in Marand (an agricultural small city), north west of Iran.

\section{Materials and Methods}

The current population-based cross-sectional study was carried out in seven health care centers in Marand, northwest of Iran, from April to August 2017. Inclusion criteria of the volunteers were as follows: 1) age above 65 years; 2) no specific diseases like swallowing or chewing disabilities; and 3) wishes to participate in the study. Sampling was carried out using cluster random sampling. The city was subdivided into seven districts on the basis of homogeneities in geographical characteristics. Each district was assumed as a cluster. The appropriate sample size for each district was calculated based on the population. Health centers in each district were selected randomly. Totally, 238 volunteers were participated in the study. Then, personal and demographic data of the participants were collected. These data included age, gender, marital status, educational level, food expenditure, housing status, smoking status, income level and family size through completing general questionnaires and then validated 110-item semi-quantitative FFQs, which reported number of food consumption per day, week and month (19). Furthermore, participants were asked to report their food intake volumes. Daily FV intake for each participant was estimated based on these data. To collect data, trained interviewers carried out faceto-face interviews. The study was approved by the Ethics Committee of Tabriz University of Medical Sciences, Tabriz, Iran. All participants provided written informed consent prior to the study enrollment

Statistical analysis: Data were statistically analyzed using SPSS Software v.17.0 (SPSS Inc., Chicago, IL, USA). Mean \pm SD (standard deviation) and frequency (\%) were used to describe quantitative and qualitative variables, respectively. Normality of the continuous variables was assessed using one-sample Kolmogorov-Smirnov test. Independent sample T-test and ANOVA were used to compare mean (SD) of the consumptions between groups. A $P$-value of less than 0.05 was considered as statistically significant. Binary logistic regression was used to investigate relationships between the FV consumption and the socioeconomic variables of the participants, including age, gender, educational, marital, economic and food expenditure statuses. To avoid infinite odds ratios, some categories were merged. For example, marital status was categorized into 'married' and 'single'.

\section{Results}

In this study, the mean age of the participants was $71.7 \pm 4.1$ years (65-80 years) and $65.5 \%$ of them were males. The mean daily consumption of FVs included $152.7 \pm 81.58 \mathrm{~g} \mathrm{day}^{-1}$ and $270.35 \pm 88.21 \mathrm{~g}$ day $^{-1}$, respectively. Nearly half of the participants (58.8\%) reported adequate FV consumption (totally $400 \mathrm{~g} \mathrm{day}^{-1}$ or further). Mean FV consumptions based on demographic variables are presented in Table 1. Results showed that the FV consumption in higher age groups was lower, compared to that in other groups $(P<0.001)$. Moreover, results showed that FV consumption in literate elderly people was higher than that in illiterate people $(P<0.001)$. However, the mean FV consumption was not significantly different between the subgroups of gender, marital status and income level, while high-income subgroup and younger participants consumed more fruits, compared to subgroups of low-income level $(P=0.05)$ and older participants $(P<0.001)$, respectively. 
Table 1. Demographic characteristics of the study population $(n=238)$

\begin{tabular}{|c|c|c|}
\hline Gender" & male & $156(65.5)$ \\
\hline Housing status" & own house & $188(79)$ \\
\hline Following a special diet. & yes & $60(25.2)$ \\
\hline Supplementation • & YES & $24(10.1)$ \\
\hline Smoking• & YES & $94(39.5)$ \\
\hline Marital status" & married & $175(73.5)$ \\
\hline Educational status" & literate & $128(53.8)$ \\
\hline Income (thousand Tomans)• & $<1500$ & $110(46.2)$ \\
\hline Family size" & $<2$ & $112(47.1)$ \\
\hline $\begin{array}{l}\text { Food expenditure (thousand } \\
\text { Tomans). }\end{array}$ & $<800$ & $152(63.9)$ \\
\hline \multirow[t]{3}{*}{ Age (years)• } & $65-70$ & $102(42.9)$ \\
\hline & $71-75$ & $72(30.3)$ \\
\hline & $76-80$ & $64(26.9)$ \\
\hline Fruit consumption (g/day) ${ }^{*}$ & & $152.77 \pm 81.58$ \\
\hline Vegetable consumption (g/day)* & & $270.35 \pm 88.21$ \\
\hline \multirow{2}{*}{$\begin{array}{l}\text { Fruits and vegetables } \\
\text { consumption (g/day)" }\end{array}$} & $<400$ & $98(41.2)$ \\
\hline & $400 \leq$ & $140(58.8)$ \\
\hline
\end{tabular}

*Described by Mean \pm SD; -describe by frequency (\%)
Significant differences were seen between the subgroups of food expenditure, gender, housing status, marital status and educational level in vegetable consumptions. Participants with higher income and food expenditure significantly consumed lower quantities of vegetables per day, compared to those with lower income $(P<0.05)$. Participants who owned personal houses consumed significantly lower vegetable quantities, compared to those who lived in rented houses $(P<0.05)$. In addition to economic variables, significant differences were seen in vegetable consumption between the age $(P<0.001)$ and gender $(P<0.05)$ subgroups. Differences in mean consumptions of fruits, vegetables and FVs were not significant between the smoker and non-smoker participants and those from small families and large families (Table 2).

Table 2. Fruit and vegetable consumptions in various study groups

\begin{tabular}{|c|c|c|c|c|c|c|c|}
\hline Variable & & Fruit consumption & $\bar{P}$ & $\begin{array}{l}\text { Vegetable } \\
\text { consumption }\end{array}$ & $\mathrm{P}$ & FV consumption & $\mathrm{P}$ \\
\hline Gender & $\begin{array}{l}\text { Male }(n=156) \\
\text { Female }(n=82)\end{array}$ & $\begin{array}{l}232.8 \pm 125.2 \\
190.5 \pm 93\end{array}$ & $0.004^{*}$ & $\begin{array}{l}371.5 \pm 112.7 \\
414 \pm 190\end{array}$ & $0.02 *$ & $\begin{array}{l}604.4 \pm 190.1 \\
604.6 \pm 176.8\end{array}$ & $0.99 *$ \\
\hline Housing status & $\begin{array}{l}\text { Rental }(n=50) \\
\text { Own house } \\
(n=188)\end{array}$ & $\begin{array}{l}181.8 \pm 78.2 \\
227.9 \pm 123.1\end{array}$ & $0.002 *$ & $\begin{array}{l}412.8 \pm 63 \\
379.1 \pm 137.2\end{array}$ & $0.01^{*}$ & $\begin{array}{l}594.7 \pm 79.3 \\
607 \pm 204.4\end{array}$ & $0.50 *$ \\
\hline $\begin{array}{l}\text { Following a } \\
\text { special diet }\end{array}$ & $\begin{array}{l}\text { Yes }(n=60) \\
\text { NO }(n=178)\end{array}$ & $\begin{array}{l}235.9 \pm 130.7 \\
212.2 \pm 111.1\end{array}$ & $0.17 *$ & $\begin{array}{l}410.5 \pm 113.7 \\
378.8 \pm 129.1\end{array}$ & $0.08^{*}$ & $\begin{array}{l}646.5 \pm 147.3 \\
590.2 \pm 194.7\end{array}$ & $0.04 *$ \\
\hline Smoking & $\begin{array}{l}\text { YES }(n=94) \\
\text { NO }(n=144)\end{array}$ & $\begin{array}{l}228.2 \pm 93.6 \\
211.7 \pm 129.2\end{array}$ & $0.25 *$ & $\begin{array}{l}379.9 \pm 90.2 \\
390.2 \pm 144.8\end{array}$ & $0.49^{*}$ & $\begin{array}{l}608.1 \pm 146.3 \\
602 \pm 207.2\end{array}$ & $0.78^{*}$ \\
\hline Marital status & $\begin{array}{l}\text { Single }(n=63) \\
\text { Married }(n=175\end{array}$ & $\begin{array}{l}185 \pm 92.7 \\
230.1 \pm 122\end{array}$ & $0.00^{*}$ & $\begin{array}{l}381.3 \pm 85.3 \\
387.9 \pm 137.9\end{array}$ & $0.65^{*}$ & $\begin{array}{l}566.3 \pm 114.8 \\
618.1 \pm 203.3\end{array}$ & $0.01^{*}$ \\
\hline Educational status & $\begin{array}{l}\text { Illiterate }(n=110) \\
\text { Literate }(n=128)\end{array}$ & $\begin{array}{l}184.2 \pm 91.5 \\
247.4 \pm 127.6\end{array}$ & $<0.001^{*}$ & $\begin{array}{l}369.1 \pm 151.2 \\
400.8 \pm 97.6\end{array}$ & $0.06^{*}$ & $\begin{array}{l}553.4 \pm 215.3 \\
648.3 \pm 144.9\end{array}$ & $<0.001^{*}$ \\
\hline $\begin{array}{l}\text { Income } \\
\text { (Thousand } \\
\text { Tomans) }\end{array}$ & $\begin{array}{l}<1500(n=110) \\
1500 \leq \\
(n=128)\end{array}$ & $\begin{array}{l}189.9 \pm 78.2 \\
242.5 \pm 137.1\end{array}$ & $<0.001^{*}$ & $\begin{array}{l}410.5 \pm 86.7 \\
377.3 \pm 141.5\end{array}$ & $0.003^{*}$ & $\begin{array}{l}586.5 \pm 137.9 \\
619.8 \pm 217.2\end{array}$ & $0.15^{*}$ \\
\hline Family size & $\begin{array}{l}<2(\mathrm{n}=112) \\
2 \leq(\mathrm{n}=126)\end{array}$ & $\begin{array}{l}211.2 \pm 97.9 \\
244.4 \pm 130\end{array}$ & $0.37 *$ & $\begin{array}{l}392 \pm 102.2 \\
380.9 \pm 144.1\end{array}$ & $0.49^{*}$ & $\begin{array}{l}603.3 \pm 150 \\
605.4 \pm 212.1\end{array}$ & $0.92 *$ \\
\hline $\begin{array}{l}\text { Food expenditure } \\
\text { (Thousand } \\
\text { Tomans) }\end{array}$ & $\begin{array}{l}<800(\mathrm{n}=152) \\
800 \leq(\mathrm{n}=86)\end{array}$ & $\begin{array}{l}204.1 \pm 101.5 \\
243.1 \pm 136.3\end{array}$ & $0.02^{*}$ & $\begin{array}{l}411.9 \pm 95.3 \\
340.7 \pm 157.6\end{array}$ & $<0.001^{*}$ & $\begin{array}{l}616.1 \pm 148 \\
583.8 \pm 236.8\end{array}$ & $0.25^{*}$ \\
\hline Age (year) & $\begin{array}{l}65-70(n=102) \\
71-75(n=72) \\
76-80(n=64\end{array}$ & $\begin{array}{l}266 \pm 139.5 \\
200.8 \pm 78.3 \\
170.3 \pm 85.9\end{array}$ & $<0.001^{* * *}$ & $\begin{array}{l}392.4 \pm 99.4 \\
422.7 \pm 124.2 \\
235.2 \pm 149.2\end{array}$ & $<0.001^{* *}$ & $\begin{array}{l}653 . \pm 174.3 \\
623 \pm 160.4 \\
505.5 \pm 192.7\end{array}$ & $<0.001 * *$ \\
\hline
\end{tabular}

FVs, fruits and vegetables; ${ }^{*} P$-values reported based on independent $\mathrm{t}$-test; ${ }^{*}{ }^{*} P$-values reported based on ANOVA test. Data described as mean \pm SD 
Table 3 shows the odds ratio of socioeconomic variables for fruit, vegetable and FV consumptions. Logistic regression analysis showed significant relationships between the gender, housing status, marital status, educational level, household income level and age with fruit consumption. The current analysis demonstrated relationships between the housing status and age with vegetable consumption. In fact, lower age in elderly people was a protective factor for vegetable consumption. Possibility of the fruit consumption in men was 2.27 times higher than that in women $(\mathrm{OR}=2.27,95 \%$ CI 1.2-5.8). Moreover, married, educated and high income participants had higher odds of fruit consumption. Of all variables, only three variables of housing status, marital status and household income level were significant for FV consumption in participants. Chances of FV consumption in participants who owned houses, married and had high incomes respectively were $3.05,2.02$ and 2.39 times greater than chances of FV consumption in other participants.

\section{Discussion}

In the present study, a high frequency of $\mathrm{FV}$ consumption was indicated. Nearly 58\% of the participants achieved WHO recommendations for daily consumption of FVs. Sabzghabaee et al. found that 38.7 and $36.8 \%$ of the Iranian elderly men and women consumed five or more servings of FVs per day, respectively (20). The inconsistency between the current results and similar results from other studies may be linked to time of data collection and city location. Marand is an agricultural regional and FV production is higher in spring. In 1998, 51\% of rural and $37 \%$ of urban elderly people consumed sufficient FV per day in the United States (13). In the current study, three variables included housing status, household income level and marital status were linked to FV consumption. Furthermore, gender, educational level and age group were associated to consumption of fruits and vegetables. However, no relationships were seen between the highlighted variables and consumption of FVs. In this study, consumption of fruits was higher than consumption of vegetables, which was affected by the economic situation such as income level and housing status.

Table 3. Relationships between the demographic, social and economic factors and consumption of fruits and vegetables

\begin{tabular}{|c|c|c|c|c|c|c|c|c|c|c|}
\hline & & \multicolumn{3}{|c|}{ fruits } & \multicolumn{3}{|c|}{ vegetables } & \multicolumn{3}{|c|}{ fruits \& vegetables } \\
\hline & & OR & CI $95 \%$ & $P$ value & OR & CI $95 \%$ & $P$ value & OR & CI 95\% & $\mathrm{P}$ value \\
\hline \multirow[t]{2}{*}{ gender } & women & ref & - & - & ref & - & - & ref & - & - \\
\hline & men & 2.27 & $1.2-5.8$ & 0.03 & 0.8 & $0.4-2.9$ & 0.66 & 1.31 & $0.6-3.2$ & 0.79 \\
\hline \multirow[t]{2}{*}{ Housing status } & rental & ref & - & - & ref & - & - & ref & - & - \\
\hline & Own house & 2.76 & $1.3-6.4$ & 0.02 & 2.79 & $1.4-7.4$ & 0.02 & 3.05 & $1.6-8.2$ & $<0.001$ \\
\hline \multirow[t]{2}{*}{ Following special diet } & No & ref & - & - & ref & - & - & ref & - & - \\
\hline & Yes & 1.66 & $0.7-3.9$ & 0.62 & 1.33 & $0.6-3.3$ & 0.74 & 1.14 & $0.6-3.0$ & 0.81 \\
\hline \multirow[t]{2}{*}{ Smoking } & No & ref & - & - & ref & - & - & ref & - & - \\
\hline & Yes & 1.08 & $0.6-2.8$ & 0.84 & 0.92 & $0.5-2.4$ & 0.87 & 1.04 & $0.6-2.5$ & 0.87 \\
\hline \multirow[t]{2}{*}{ Marital status } & Single & ref & - & - & ref & - & - & ref & - & - \\
\hline & Married & 2.25 & $1.1-6.3$ & 0.04 & 1.86 & $0.6-3.9$ & 0.15 & 2.02 & $0.9-6.0$ & 0.04 \\
\hline \multirow[t]{2}{*}{ Educational status } & Illiterate & ref & - & - & ref & - & - & ref & - & - \\
\hline & Literate & 2.64 & $1.4-6.2$ & 0.02 & 0.98 & $0.5-2.7$ & 0.88 & 1.28 & $0.6-2.8$ & 0.65 \\
\hline \multirow{2}{*}{$\begin{array}{l}\text { Income (Thousand } \\
\text { Tomans) }\end{array}$} & $1200<$ & ref & - & - & ref & - & - & ref & - & - \\
\hline & $1200 \geq$ & 3.04 & $1.6-8.1$ & $<0.001$ & 1.68 & $0.6-4.0$ & 0.41 & 2.39 & $1.3-6.1$ & 0.02 \\
\hline \multirow[t]{2}{*}{ Family size } & $2>$ & ref & - & - & ref & - & - & ref & - & - \\
\hline & $2 \leq$ & 2.11 & $0.9-4.6$ & 0.48 & 1.74 & $0.7-4.0$ & 0.29 & 2.01 & $0.9-5.9$ & 0.55 \\
\hline \multirow{2}{*}{$\begin{array}{l}\text { Food expenditure } \\
\text { (Thousand Tomans) }\end{array}$} & $800<$ & ref & - & - & ref & - & - & ref & - & - \\
\hline & $800 \geq$ & 2.16 & $0.8-6.2$ & 0.53 & 1.78 & $0.6-4.4$ & 0.12 & 2.07 & $0.9-6.1$ & 0.31 \\
\hline \multirow[t]{3}{*}{ Age group } & $76-80 y$ & ref & - & - & ref & - & - & ref & - & - \\
\hline & $71-75 y$ & 1.52 & $0.7-4.3$ & 0.71 & 2.37 & $1.2-6.5$ & 0.03 & 1.64 & $0.6-3.8$ & 0.31 \\
\hline & $65-70 y$ & 3.63 & $1.7-5.2$ & $<0.001$ & 1.56 & $0.6-3.9$ & 0.55 & 1.74 & $0.7-4.0$ & 0.29 \\
\hline
\end{tabular}

FVs, fruits and vegetables; $P$-values reported based on binary logistic regression 
Individual and household income levels are strongest predictors of FV consumption in elderly people (21) since fruit price is higher than vegetable price in Iran. Other studies have shown relationships between the household economic status and dietary patterns with more fruits and vegetables (22-24). An analysis on national survey data of Iranian provinces from 2007 to 2009 showed that a higher socioeconomic statuses were associated to greater consumptions of FVs. Moreover, data revealed that older ages were associated to lower consumptions of fruits (25).

Of the social variables, only marital status was linked to the consumption of FVs. Various studies have shown that marriage is positively linked to consumption of FVs in older men and women (24). For example, Payette and et al. reported that older married adults were most likely to achieve recommended portions of FVs, compared to widowed and divorced elderly people (26). In the current study, marriage significantly increased chances of higher consumptions of fruits, vegetables and FVs. Family support is a possible reason for these findings due to the pivotal role of family supports in healthy diets $(12,14)$. Furthermore, study findings showed that consumption of FVs decreased with age. Similar findings have been shown in developed and developing countries $(12,13,27)$. In the present study, no significant relationships were seen between the gender and consumption of FVs. However, patterns of consumption varied within the different sex groups. Therefore, men consumed higher fruits and women consumed higher vegetables compared to the opposite sex group. As shown in this study, male gender increases the chance of fruit consumption over the median level, compared to female gender. These findings were similar to findings from other studies in Iran (12). Previous studies in other countries reported contradictory findings. Studies reported higher consumptions of FVs by men (15), while others reported higher consumptions of FVs by women (16, 28). These differences might be due to cultural differences between the nations. Studies have demonstrated that the educational level is positively correlated with healthy diets that mostly consist of FVs $(21,29,30)$. This is because higher educational levels can increase personal abilities to acquire or understand overall health information and, in particular, the nutritional knowledge necessary to promote good health. In the current study, the mean consumption of fruits and FVs in literate group was more than that in illiterate group. Moreover, literacy significantly increased the odds of consuming fruits at higher levels than the median. However, relationships between the literacy and consumption of FVs were not significant; as shown by other studies $(18,20)$.

\section{Conclusion}

In general, the current study has demonstrated important roles of socioeconomic factors such as household income level and marital status on consumption of FVs. Fruit consumption was associated to age, gender, housing status, marital status, educational level and household income level. Furthermore, high vegetable consumption was associated to housing status as an important socioeconomic parameter. Therefore, results suggest that future policies and interventions to improvement of FV consumption in elderly people should consider socioeconomic inequalities.

\section{Financial disclosure}

The authors declared no financial interest.

\section{Funding/Support}

This manuscript has been reviewed and approved by all the contributing authors. The authors declare no conflict of interest.

\section{References}

1. Organization WH. Increasing fruit and vegetable consumption to reduce the risk of non-communicable diseases. WHO technical staff report, 2014.

2. Ledoux T, Hingle MD, Baranowski T. Relationship of fruit and vegetable intake with adiposity: a systematic review. Obes Rev 2011;12: 143-50.

3. Bazzano LA, Li TY, Joshipura KJ, Hu FB. Intake of fruit, vegetables, and fruit juices and risk of diabetes in women. DIABETES CARE 2008;31:1311-7.

4. Stefler D, Malyutina S, Nikitin Y, Nikitenko T, Rodriguez-Artalejo F, Peasey A, et al. Fruit, vegetable intake and blood pressure trajectories in older age. $J$ Hum Hypertens 2019:1.

5. Yoshizaki T, Ishihara J, Kotemori A, Yamamoto J, Kokubo Y, Saito I, et al. Association of Vegetable, Fruit, and Okinawan Vegetable Consumption With Incident Stroke and Coronary Heart Disease. J Epidemiol 2019:JE20180130.

6. Farvid MS, Chen WY, Rosner BA, Tamimi RM, Willett WC, Eliassen AH. Fruit and vegetable consumption and breast cancer incidence: Repeated 
measures over 30 years of follow- up. Int $\mathbf{J}$ Cancer 2019;144:1496-510

7. Xie H-L, Wu B-H, Xue W-Q, He M-G, Fan F, Ouyang $\mathrm{W}-\mathrm{F}$, et al. Greater intake of fruit and vegetables is associated with a lower risk of osteoporotic hip fractures in elderly Chinese: a 1: 1 matched casecontrol study. Osteoporos Int 2013;24:2827-36.

8. Marengoni A, Winblad B, Karp A, Fratiglioni L. Prevalence of chronic diseases and multimorbidity among the elderly population in Sweden. Am J Public Health 2008;98:1198-200.

9. Naughton C, Bennett K, Feely J. Prevalence of chronic disease in the elderly based on a national pharmacy claims database. Age Ageing 2006;35:633-6.

10. Who J, Consultation FE. Diet, nutrition and the prevention of chronic diseases. World Health Organ Tech Rep Ser 2003;916(i-viii).

11. Esteghamati A, Noshad S, Nazeri A, Khalilzadeh O, Khalili M, Nakhjavani M. Patterns of fruit and vegetable consumption among Iranian adults: a SuRFNCD-2007 study. Br J Nutr 2012;108:177-81.

12. Salehi L, Eftekhar H, Mohammad K, Tavafian SS, Jazayery A, Montazeri A. Consumption of fruit and vegetables among elderly people: a cross sectional study from Iran. Nutr. J. 2010;9:1.

13. Blanck HM, Gillespie C, Kimmons JE, Seymour JD, Serdula MK. Trends in fruit and vegetable consumption among US men and women, 1994-2005. Prev Chronic Dis 2008 Apr;5(2).

14. Li Y, Li D, Ma C-y, Liu C-Y, Wen Z-M, Peng L-p. Consumption of, and factors influencing consumption of, fruit and vegetables among elderly Chinese people. Nutrition 2012;28:504-8.

15. Peltzer K, Phaswana-Mafuya N. Fruit and vegetable intake and associated factors in older adults in South Africa. Global health action 2012;5: 1250-5.

16. Doubova SV, Sánchez-García S, Infante-Castañeda C, Pérez-Cuevas R. Factors associated with regular physical exercise and consumption of fruits and vegetables among Mexican older adults. BMC Public Health 2016;16:952-58.

17. Asgari F, Haghazali M, Heydarian H. Noncommunicable diseases risk factors surveillance in Iran. 2009 .

18. Viebig RF, Pastor-Valero M, Scazufca M, Menezes PR. Fruit and vegetable intake among low income elderly in the city of São Paulo, Southeastern Brazil. Rev Saude Publica 2009;43:806-13.

19. Mohammadifard N, Omidvar N, Houshiarrad A, Neyestani T, Naderi G-A, Soleymani B. Validity and reproducibility of a food frequency questionnaire for assessment of fruit and vegetable intake in Iranian adults. J Res Med Sci 2011;16(10).

20. Sabzghabaee AM, Mirmoghtadaee P, Mohammadi M. Fruit and vegetable consumption among community dwelling elderly in an Iranian population. Int $\mathbf{J}$ Prev Med 2010;1(2)

21. Nicklett EJ, Kadell AR. Fruit and vegetable intake among older adults: A scoping review. Maturitas. 2013;75:305-12.

22. Riediger ND, Moghadasian MH. Patterns of fruit and vegetable consumption and the influence of sex, age and socio-demographic factors among Canadian elderly. J Am Coll Nutr 2008;27:306-13.

23. Drewnowski A, Darmon N. Food choices and diet costs: an economic analysis. J Nutr 2005;135:900-4.

24. Bowman S. Low economic status is associated with suboptimal intakes of nutritious foods by adults in the National Health and Nutrition Examination Survey 1999-2002. NUTR RES. 2007;27:515-23.

25. Kiadaliri AA. Demographic and socioeconomic differences in fruit and vegetables consumption, 20072009: a province-level study in Iran. Int. J. Prev. Med 2013;4(7):831-840

26. Payette H, Shatenstein B. Determinants of healthy eating in community-dwelling elderly people. Can J Public Health 2005:S27-S31.

27. Tamers S, Agurs-Collins T, Dodd K, Nebeling L. US and France adult fruit and vegetable consumption patterns: an international comparison. Eur J Clin Nutr 2009;63:11-7.

28. Baker AH, Wardle J. Sex differences in fruit and vegetable intake in older adults. Appetite. 2003;40(3):269-75.

29. Pala V, Sieri S, Masala G, Palli D, Panico S, Vineis P, et al. Associations between dietary pattern and lifestyle, anthropometry and other health indicators in the elderly participants of the EPIC-Italy cohort. Nutr Metab Cardiovasc Dis 2006;16:186-201.

30. Sahyoun NR, Zhang XL, Serdula MK. Barriers to the consumption of fruits and vegetables among older adults. J Nutr Elder. 2006;24:5-21. 